\title{
Low Back Pain in Athletes
}

\author{
Javad Mortazavi ${ }^{1}$; Jayran Zebardast ${ }^{2}$; Babak Mirzashahi ${ }^{1, *}$

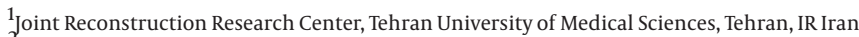 \\ 2 Imam Khomeini Hospital Complex, Tehran University of Medical Sciences, Tehran, IR Iran \\ ${ }^{*}$ Corresponding author: Babak Mirzashahi, Imam Khomeini Hospital Complex, Tehran University of Medical Sciences, Tehran, IR Iran. Tel: +98-2161192767, Fax: +98-2166581653, \\ E-mail: babakmirzashahi@yahoo.com
}

Received: April 10, 2014; Accepted: July 27, 2014

\begin{abstract}
Context: Low Back Pain (LBP) in athletes is common and has a broad spectrum of differential diagnoses that must be taken in to account when a clinician approaches the patient with LBP. The physicians should take into account spinal and extra spinal causes of low back pain in athletes.

Evidence Acquistion: A literature review was performed for the years 1951 through 2013. Keywords used were Low Back Pain and Athletes. We searched MEDLINE, EMBASE, OVID, PUBMED, the Cochrane Library, ELSEVIER, and the references of reviewed articles, for Englishlanguage of Low Back Pain in Athletes.

Results: The two most common causes of LBP arising from spine in athletes are degenerative disc disease and spondylolysis with or without listhesis. Although most athletes, respond well to conservative treatment, surgical treatment is indicated when conservative treatment failes.

Conclusions: The major concern in athletes with LBP is return to play and previous level of their activity after treatment. There is insufficient evidence regarding this issue in literature to define the optimal time of return to play following treatment.
\end{abstract}

Keywords: Athletes; Low Back Pain; Degenerative Disc; Spondylolysis; Treatment

\section{Context}

The incidence of low back pain (LBP) in young athletes has been reported in a wide range in literature, including numbers as low as one to as high as thirty percent (1-3). Many factors such as kind of sport, gender, training intensity, frequency and technique affect the rate of low back pain in athletes (4-7). In spite of the self-limiting nature of disease in most cases, many athletes experience long lasting symptoms which could affect their professional life $(5,8,9)$. The most common cause of LBP in athletes is degenerative disc disease (DDD) and sponylolysis (10-14). Finding the exact cause of pain in athletes is not always feasible and it may create challenges for treating physicians in both diagnosis and management (10). Therefore, physicians should lead a comprehensive approach to the patient with LBP and need to keep in mind the less common causes of LBP in athletes such as stress fracture of sacrum or facet joints (11).

\subsection{Epidemiology}

LBP is a symptom and not a diagnosis; therefore, it is important to interpret the epidemiology of LBP in athletes in the light of this important point. It is also important to take into account that LBP is self-limiting in many patients and thus it is difficult to attribute this to a known underlying abnormality $(4,10)$ LBP is a common cause of lost playing time in competitive athletes. Low back pain is an important and common cause of missing games in athletes (11-15). According to McCarroll et al. (12), 30\% of football players (44 of 145 college football players) lost playing time due to LBP (12). According the literature review, the prevalence of LBP in athletes has been reported between $1 \%$ to $30 \%$, and also, $10-15 \%$ of all sport injuries are low back injuries (16-19). Granhed et al. reported that the prevalence of LBP in wrestlers was significantly higher than the age-matched population (59\% vs 31\%) (3). According to Sward et al. LBP in elite gymnasts was higher than control group (79\% vs 38\%) (11). In other sports, LBP has lower incidence and the prevalence of LBP in soccer, tennis, football, golf and weightlifting has been reported to be $30-40 \%(21,23)$. In some types of sports, for instance in gymnasts and wrestlers LBP is more common and reported $70 \%$ and $59 \%$ respectively $(3,8,11,12)$. Likewise Hainline et al. reported that $38 \%$ of professional tennis players missed at least one tournament because of LBP (13).

\subsection{Differential Diagnosis}

Both spinal and non-spinal cause of LBP must be considered in evaluating the athletes with LBP (14-17). Table 1 shows etiologies of LBP which could be intrinsic to spine or related to pathology in adjacent organs. Therefore, a

Copyright ( 2015, Sports Medicine Research Center. This is an open-access article distributed under the terms of the Creative Commons Attribution-NonCommercial 4.0 International License (http://creativecommons.org/licenses/by-nc/4.0/) which permits copy and redistribute the material just in noncommercial usages, provided the original work is properly cited. 
Table 1. Differential Diagnosis of LBP in Athletes $(14-17,24)$

\begin{tabular}{lc}
\hline Spinal Causes & Adjacent Organs \\
\hline $\begin{array}{l}\text { Muscle strain/ligament } \\
\text { sprain }\end{array}$ & $\begin{array}{c}\text { Pelvic organs (e.g. ovarian } \\
\text { cysts) }\end{array}$ \\
\hline $\begin{array}{l}\text { Degenerative Disc Disease } \\
\text { Isthmic spondylolysis/ } \\
\text { listhesis }\end{array}$ & $\begin{array}{c}\text { Renal disease } \\
\text { Ring apophyseal injury } \\
\text { (adolescents ) }\end{array}$ \\
\hline $\begin{array}{l}\text { Stress fracture of sacrum/ } \\
\text { Facet (14) }\end{array}$ & Hipdominal Aortic Aneurysm \\
\hline $\begin{array}{l}\text { Disc Herniation } \\
\text { Fracture of vertebrae }\end{array}$ \\
\hline Infection \\
Tumors \\
\hline Sacralization of L5 \\
\hline
\end{tabular}

broad spectrum of differential diagnoses should be considered. However, in this review we focused on the two most common causes of LBP in athletes, namely, degenerative disc disease and spondylolisthesis.

\section{Evidence Acquisition}

A literature search was performed for the years 1951 through 2013. Keywords used were Low Back Pain and Athletes. We searched MEDLINE, EMBASE, OVID, PUBMED, the Cochrane Library, ELSEVIER, and the references of reviewed articles, for English-language of Low Back Pain in Athletes. RCT $(n=9)$, case control $(n=4)$, review article $(n=45)$, cohort $(n=1)$, systematic review $(n=4)$, case series $(n=11)$, cross sectional $(n=26)$ and case report $(n=1)$. Exclusion criteria were papers presented in the conferences and papers without full text and articles that had been written in other languages except english (Figure 1).

\section{Results}

\subsection{Degenerative Disc Disease}

The exact relationship between degenerative disc disease (DDD) and LBP remains unclear because many radiographic findings of degenerative disc disease are found in the asymptomatic general population (18). Micheli et al. reported that acute disc herniation occurs in only $11 \%$ of young athletes with LBP (17).

Pathogenesis: According to the available literature, stress within the anulus can cause tearing within it (19). Circumferential tears occur first, and with continued stress these can progress to radial tears, which is detected as a high intensity zone (HIZ) by Magnetic Resonance Imaging (MRI) (19-25) or as leakage of contrast medium within the posterior aspect of the annulus on a discogram $(19,25,26)$. At this stage plain radiographs demonstrate a mild decrease in disc height, MRI can reveal decreased signal intensity in the disc, and these changes result in more loads on the posterior facet joints, subsequently causing degeneration of the articular surfaces. With time, advanced degenerative changes, such as osteophyte formation in both the disc and the facets, are an attempt at autostabilization (18, 19). Several studies have characterized nociceptive microinnervation of anterior and posterior aspect of the annulus and facet joints (21-23).

\subsubsection{Degenerative Disc Disease and Sports}

Every sport places unique demands on the lumbar vertebrae and consequently, the intervertebral disc (27-29).

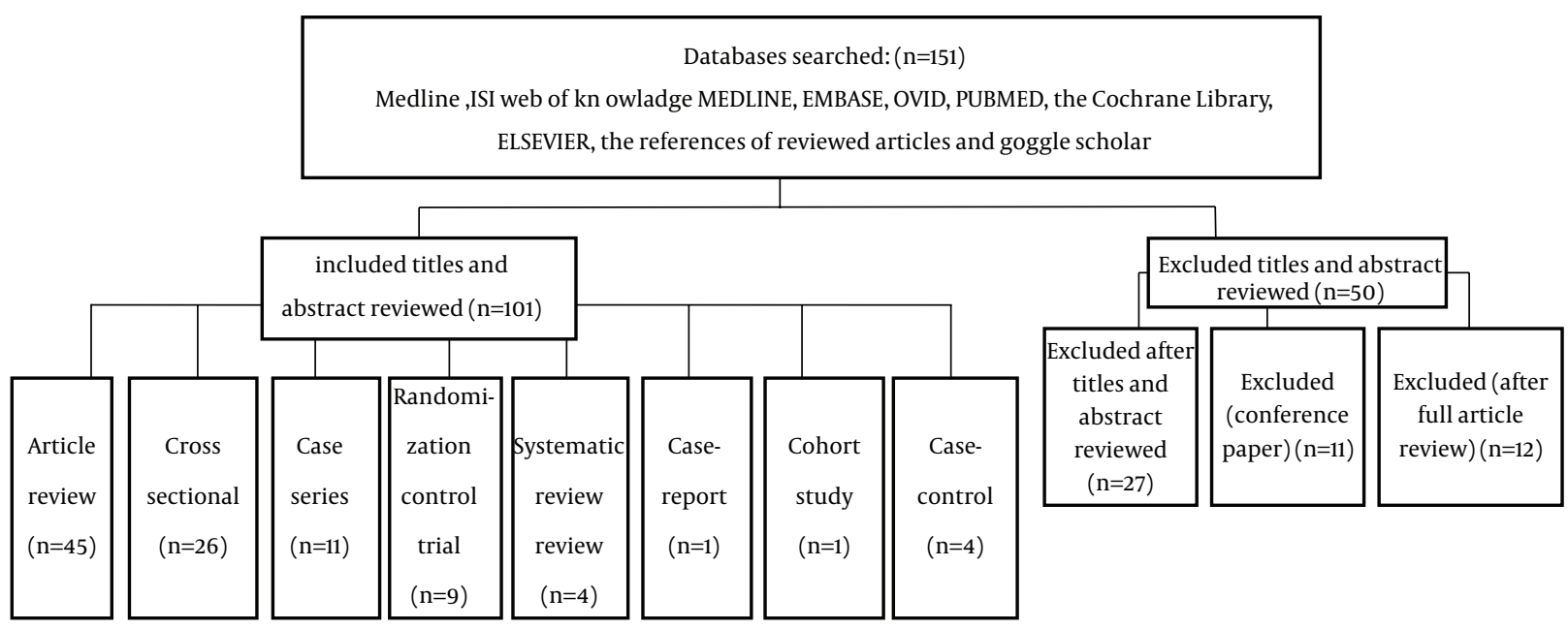

Figure 1. illustrates the structure of the literature review. 
Hosea et al. showed that a golf swing, a primarily torsional activity, produces 7500 and $6100 \mathrm{~N}$ of compressive force across the L3-L4 disc in professional and amateur players (30). Hosea and Hannafin also estimated maximal lumbar compressive force to be about $6100 \mathrm{~N}$ in rowers (31). According the studies of Gatt et al. (32) and Cholewicki et al. (33) who measured forces in L4-L5 motion segment during blocking maneuvers in 5 football linemen and 57 competitive weight lifters, respectively, the average peak compressive load was $>8600 \mathrm{~N}$ and $>17000 \mathrm{~N}$. Cappozzo et al. found that during half-squat lifting of a weight about 1.6 time of body weight compressive load across the L3-L4 motion segment was about ten times body weight (approximately $7000 \mathrm{~N}$ for an average $70 \mathrm{~kg}$ personal). These studies showed that increasing lumbar flexion was the most effective coincidence (34). According to the Sward et al. (11) and Ong et al. (35) studies participation in sport is a probable risk factor for development of disc degeneration. Sward et al. (11) showed that in $75 \%$ of elite gymnasts degenerative radiographic changes in lumbar spine was detected, contrary to $31 \%$ of control group. Similarly, Ong et al. (35) reported degenerative changes in $58 \%$ of athletes compared with $38 \%$ of control group, and this degenerative change was more prominent at L5-S1 disc (the most affected level was L5-S1 disc). Other factors that may accelerate disc degeneration are type and intensity of the sports (29, 35-37). Sward et al. demonstrated that DDD was more common in male gymnasts than players in other sports (38). Bartolozzi et al. (5) showed that although the radiographic evidence of degenerative changes was more common in volleyball players with improper technique than in those who used proper technique (62\% vs $21 \%$ ), the rate of LBP was not higher in the former group (5). Videman et al. (1) showed that degenerative changes were more common in weight lifters compared to football players and also in the former the upper lumbar levels were more affected while in the later, lower lumbar levels $(1,39,40)$. According to the studies of Lundin (9), Sward (11), Kujala (7), Ogon (36) and Videman (1), there is an association between imaging findings and the $\operatorname{LBP}(1,9,11,41,42)$. They found that decreased disc-space height in X-Ray, decreased signal intensity within the disc on MRI, ring apophyseal injury in X-Ray, severe end-plate degeneration and disk degeneration on MRI, were the most correlated imaging findings with LBP.

\subsubsection{Treatment}

Most patients improve with non-operative treatment because the majority of athletes with LBP have a benign source of pain $(37,43-45)$. There are many different modalities for non-operative treatment including nonsteroidal anti-inflammatory drugs (NSAIDs), heat, ultrasound laser therapy, NSAIDs, steroids, manipulation, traction, injections, acupuncture, massage, back school, exercise, with different recommendations in the literature $(37,43$,
44, 46-49). Heat can be applied to the low back pain with water bottle and bath, hot packs, steam, saunas and electric pads. There is moderate evidence according to the Cochran review, that support effectiveness of heat in reducing acute and sub-acute low back pain. With addition of exercise, pain can be further decreased, (50) specially if superficial heat is applied in the first week $(51,52)$.There are no systematic and Cochran reviews for ultrasound (53-55). Only one small nonrandomized control trial has shown that ultrasound is more effective than pain killers in reducing pain in patients with acute low back pain (53). A Cochran review of small studies found insufficient data to support the effectiveness of laser therapy in low back pain which is result of the heterogenicity of populations, dosage and technique of laser application (56). A large Cochran review of 65 trials of NSAIDs and COX-II inhibitors in treatment of low back pain found that both of them were more effective than the placebo in reducing pain in patients with acute and chronic low back pain. Although both of them have many known side effects, NSAIDs have more traditional side effects and COX-II inhibitors have potentially more cardiovascular side effects (57). There is no clear evidence about the effectiveness of antidepressant drugs and opioids in treatment of acute and chronic low back pain $(58,59)$. According to the three high quality trials, systemic steroids were not more effective than placebo in treatment of low back pain $(60,61)$. In patients with low back pain without radicular pain the effect of a single dose intramuscular injection in pain relief through a month was the same as placebo (61). A Cochran review of 20 randomized control trials (RCTs) (total population $=2674)$ for spinal manipulative therapy $($ SMT) for treatment of acute low back pain found that SMT was not more effective than other recommended therapies and interventions (62). A Cochran review of 32 RCTs (total participants $=2762$ ) for traction in low back pain with or without sciatica indicated that traction, either alone or in combination with other treatments, has little or no impact on pain intensity, functional status, global improvement and return to work among people with LBP. There is only limited-quality evidence from studies with small sample sizes and moderate to high risk of bias. The effects shown by these studies are small and are not clinically relevant (63). A Cochran review of 18 RCTs of 1179 participants for injection therapy for sub-acute and chronic low back pain showed that there is no strong evidence for or against the effectiveness of injection of steroid, local anesthetics, indomethacin, sodium hyaluronate and B12 in treatment of low back pain (64). There are low to very low-quality evidence for effectiveness of Botulinum injection in treatment of low back pain in a 2011 Cochran review (65). A Cochran review of 35 RCTs for effectiveness of acupuncture for acute low-back pain did not conclud firmly that it reduced pain, however, for chronic low-back pain, acupuncture is more effective than no treatment immediately after treatment and in the short-term only. The data suggest that acupuncture and dry-needling in 
combination with other therapies may reduce pain in chronic low-back pain and it is not better than conservative treatment (66). According to a Cochran review of 13 RCTs, massage might be useful in patients with sub-acute and chronic non-specific low-back pain, especially in combination with other modalities such as exercise and education (67). The insufficient strong evidence shows that acupuncture massage is more beneficial than classic massage, but this needs more studies and confirmation (66). There is moderate evidence suggesting superiority of back schools over other conservative treatments in reducing pain (68). A Cochran review showed that in an occupational setting, back schools were more effective than exercise, manipulation, myofascial therapy or advice; and placebo in decreasing pain, returning to work and improving function in patients with chronic LBP status, in the short and intermediate-term $(68,69)$. A Cochran review of 61 RCTs found that exercise in acute low back pain had the same effect on low back pain in comparative to no treatment or conservative therapy. In chronic low back pain, exercise, reduced pain slightly and in subacute low back pain there is weak evidence regarding effectiveness of exercise in decreasing pain (70). Table 2 describes strength of recommendation for these modalities.

\subsubsection{Operative Treatment}

The main indications for surgical treatment in athletes with LBP are pain correlated with imaging studies, and failure of conservative treatment after 4-6 months $(37,43,44)$. Various surgical options have been described to decreased pain. These consist of posterolateral fusion, interbody fusion (ALIF, TLIF, PLIF, XLIF) techniques, 360 degrees fusion (Anterior and posterior). Literature review shows that fusion rate with interbody fusion technique is higher than posterolateral technique $(73,85,88,89,94)$. Whoever the effect of this on longterm outcome is elusive (39-52). Because it has been thought that the pathology of DDD is in the disc, more surgeons prefer inter body fusion techniques. In some studies good or excellent results have been reported $(73,76,89,94)$.

\subsubsection{Return to Play}

The main concern for athletes with LBP is return toplay after either conservative or operative treatment. There is lack of evidence concerning the optimal time of return to play $(44,95,96)$. There is only some evidence regarding optimal time of return to play that are based on expert opinions $(44,95)$. According to an expert opinion guideline on return to play (RTP), patients with LBP undergoing conservative therapy should achieve full range of motion of spine and at least $80 \%$ of muscle strength before return to play $(44,95)$. For patients with persistent pain nonresponsive to conservative treatment, progressive listhesis or developing neurologic deficit surgical treatment must be considered. There are many different surgical technique options in patients who are candidates for surgical treatment, from simple posterolateralinsitu fusion with or without instrumentation, to more advanced and complicated surgical technique such as neurologic decompression accompanied by circumferential fusion. Description of these techniques in details is beyond the scope of this article. Athletes who underwent fusion with any kind of surgical technique should wait at least one year until radiographic evidence of union is revealed before RTP $(44,95)$. If conservative treatment failed to reduce pain in athletes, surgical treatment is indicated. There are a wide variety of surgical techniques, however, the two most common surgeries which are discussed more in this article, are microdisectomy and fusion techniques either posterolaterally or interbody fusion techniques $(44,95)$.After spinal fusion due to discogenic pain as a result of degenerative disc disease, the athletes should wait one year before returning to play $(44,95,96)$. Many surgeons advise the athletes to avoid participating in contact sport after fusion (96). Iwamoto et al. reported that $79 \%$ of athletes with disc herniation returned to play following conservative therapy in an average time of 4.7 months, and $85 \%$ of those treated surgically returned to

Table 2. Strength of Recommendation for Non-Operative Modalities (10) ${ }^{\mathrm{a}}$

\begin{tabular}{|c|c|c|c|}
\hline A & B & C & Expert based Recommendation \\
\hline Manipulation $(69,70)$ & Heat $(71,72)$ & Acupuncture (73) & TENS (74) \\
\hline \multirow[t]{7}{*}{$\operatorname{NSAIDS}(75)$} & Exercise (76) & Back school (76) & Traction $(77,78)$ \\
\hline & Corestabilization $(72,73,79)$ & Low-level laser therapy (80) & Ultrasound $(68,77,80-82)$ \\
\hline & Muscle relaxants $(70,79,83,84)$ & Massage $(77,85)$ & \\
\hline & Opioids (86) & Steroid (87-90) & \\
\hline & Antidepressant $(91,92)$ & & \\
\hline & Injection (93) & & \\
\hline & Bracing (80) & & \\
\hline
\end{tabular}

a Abbreviations: A, Consistent, Good Quality Patient-Oriented Evidence; B, Inconsistent or limited-Quality Patient-Oriented Evidence; C, Consensus, Disease-Oriented Evidence, Usual Practice, Expert Opinion or Case Series;. 
activity in 5.2 to 5.8 months (96). Most authors believe that athletes should wait until there is radiographic evidence of fusion, complete or nearly complete relief of pain and achievement of more than $80 \%$ of strength, flexibility and endurance of spinal muscle and spine, before they return to previous activity level (44).

\subsection{Spondylolysis and Spondylolisthesis}

Generally speaking spondylolysis is a bony defect ofpars inter-articularis and classified to three subtype of stress fracture, acute traumatic fracture and elongated pars, that is a result of recurrent micro fracture of pars due to micro trauma and subsequent micro motion and union and repeated this event in the life time $(72,74,97,98)$. The most common sites of spondylolysis are L5 (in 85-95\% of cases) and L4 (in 5-15\% of patients) vertebra (72, 81, 98, 99). Most cases are detected incidentally because ofthe asymptomatic nature of disease $25 \%$ of symptomatic patients may develop spondylolisthesis (79). In some sports the prevalence of spondylolysis seems to be higher. According to the Rossi and Dragoni study prevalence of spondylolysis in divers, wrestlers and weight lifters was $43 \%$, 30\% and 23\%, respectively (75). Soler and Calderon (82) reported a prevalence of $27 \%, 17 \%$ and $17 \%$ in throwing athletes, gymnasts, and rowers, in the same order (82). In terms of clinical manifestation LBP is the most common symptom. Some patients may report radicular pain and hamstring tightness (82). In physical examination, hyperextension of lumbar spine increases the pain, in inspection of the patient who is standing, hyperlordosis of lumbar spine is evident which could be a result of spondylolisthesis or exaggerated pelvic incidence and sacral inclination with higher grade spondylolisthesis, heart shaped buttock, step off on lower back, point tenderness, positive straight leg raise test due to either hamstring tightness or nerve root tension may exist $(82,100)$. Neurologic examination is usually normal $(44,82,100)$.

\subsubsection{Diagnosis}

For diagnosis of spondylolysis in athletes, high suspicion of physician is necessary $(44,90,93)$. Radiographic modalities start with AP, lateral and Right and left oblique of lumbosacral junction (90). Another useful view is coned-down lateral X-Ray of lumbosacral junction by which $85 \%$ of spondylysis is appreciable (98). Spondylolisthesis has been classified by myerding (71), as grade I indicating < 25\%; grade II, $25-50 \%$; grade III, 50-75\%; grade IV, 75-100\% and grade V, spondyloptosis (79, 98).When plain radiographs in suspected patients fail to detect the spondylolytic defect then more sophisticated modalities such as bone scan, single- photon- emission computed tomography (SPECT), or MRI should be used (100). SPECT also is useful in differentiating symptomatic from asymptomatic pars defects (100). CT scan is more sensitive than plain X-Ray. By CT scan differentiation between acute (fresh fracture site edges) and chronic pars defect (with sclerotic and blunt edges) is feasible. In a patient with LBP and suspected spondylolysis and negative $\mathrm{X}$ Ray, SPECT should be recommended. If SPECT is positive then CTscan for appreciation of chronicity of pars lesion should be performed $(83,100,101)$.

\subsubsection{Treatment}

Most patients with spondylolysis improve with conservative treatment (90). Non-operative treatment includes short-term rest and/or brace followed by physiotherapy $(44,90,93)$. In most cases symptomatic patients are successfully managed with non-operative measures (80, 84, 92). For adolescent athletes with persistent symptoms despite conservative therapy surgical treatment, pars repair, in situ posterolateral fusion, interbody fusion techniques and circumferential fusion produce satisfactory results $(44,90)$

\section{Conclusions}

LBP in athletes is common and has a broad spectrum of differential diagnoses that must be taken in to account when a clinician approaches the patient with LBP. The physicians should take into account spinal and extra-spinal causes of low back pain in athletes. The two most common causes of LBP arising from the spine, in athletes are DDD and spondyloysis with or without listhesis (14-17). Although most atheletes, with LBP whether resulting of DDD or spondylolysis respond well to conservative treatment (44), there are many options for nonsurgical treatment which have been discussed in detail with the last evidence regarding their effectiveness in reducing pain in patients complaining of LBP. When conservative treatment failes, surgical treatment is indicated. On the other hand, intractable pain, progressive listhesis in spite of conservative treatment, or development of neurologic deficit, especially if it is progressive, are the surgical indications in athletes $(37,43,44)$. There are different kinds of surgical technique, including simple posterolateral fusion, interboby fusion techniques (PLIF, TLIF, ALIF, XLIF), and circumferential fusion. Recently minimaly invasive techniques instead of conventional techniques are developing fastly, which might have benefits for athletes to return to play earlier in comparison to conventional techniques. However this concept needs large future trials $(73,85,89,94)$. It should be emphasized that with any kind of surgical technique the patients need time for fusion and healing, which is a year according to most references $(44,95)$. The major concern in athletes with LBP is return to play and previous level of their activity after treatment. There is insufficient data regarding this issue in literature to define the optimal time to return to play following treatment. To our knowledge some authors recommend $(44-50,73,85,89,94)$ return to play when: the athletes are pain free, when they have near normal function of spine in terms of muscle strength, flexibility 
and endurance (44).For patients who underwent fusion whether due to DDD or spondylolysis, with any kind of surgical technique, either conventional or new minimaly invasive techniques, RTP guidelines recommend waiting time of at least one year before return to play $(44,50$, $93,95)$. Most authors believe that when athletes are painfree they can return to play, regardless of whether there is radiographic evidence of pars healing $(83,90,101)$. According to RTP guidelines patients with spondylolysis and low grade spondylolisthesis (grade I) should rest 4-6 weeks and then achieve full range of motion before return to play (44).

\section{References}

1. Videman T, Sarna S, Battie MC, Koskinen S, Gill K, Paananen H, et al. The long-term effects of physical loading and exercise lifestyles on back-related symptoms, disability, and spinal pathology among men. Spine (Phila Pa 1976). 1995;20(6):699-709.

2. Hickey GJ, Fricker PA, McDonald WA. Injuries to elite rowers over a 10-yr period. Med Sci Sports Exerc. 1997;29(12):1567-72.

3. Granhed $\mathrm{H}$, Morelli B. Low back pain among retired wrestlers and heavyweight lifters. Am J Sports Med.1988;16(5):530-3.

4. Dreisinger TE, Nelson B. Management of back pain in athletes. Sports Med.1996;21(4):313-20.

5. Bartolozzi C, Caramella D, Zampa V, Dal Pozzo G, Tinacci E, Balducci F. [The incidence of disk changes in volleyball players. The magnetic resonance findings]. Radiol Med.1991;82(6):757-60.

6. Johnson AW, Weiss CI, Stento K, Wheeler DL. Stress fractures of the sacrum. An atypical cause of low back pain in the female athlete. Am J Sports Med. 2001;29(4):498-508.

7. Kujala UM, Kinnunen J, Helenius P, Orava S, Taavitsainen M, Karaharju E. Prolonged low-back pain in young athletes: a prospective case series study of findings and prognosis. Eur Spine J. 1999;8(6):480-4

8. Jackson DW, Wiltse LL, Cirincoine RJ. Spondylolysis in the female gymnast. Clin Orthop Relat Res. 1976;(117):68-73.

9. Lundin O, Hellstrom M, Nilsson I, Sward L. Back pain and radiological changes in the thoraco-lumbar spine of athletes. A longterm follow-up. Scand J Med Sci Sports. 2001;11(2):103-9.

10. Nachemson AL. Newest knowledge of low back pain. A critical look. Clin Orthop Relat Res. 1992;(279):8-20.

11. Sward L, Hellstrom M, Jacobsson B, Nyman R, Peterson L. Disc degeneration and associated abnormalities of the spine in elite gymnasts. A magnetic resonance imaging study. Spine (Phila Pa 1976). 1991;16(4):437-43.

12. McCarroll JR, Miller JM, Ritter MA. Lumbar spondylolysis and spondylolisthesis in college football players. A prospective study. Am J Sports Med.1986;14(5):404-6.

13. Hainline B. Low back injury. Clin Sports Med.1995;14(1):241-65.

14. Mann DC, Keene JS, Drummond DS. Unusual causes of back pain in athletes. J Spinal Disord. 1991;4(3):337-43.

15. Delvaux. K., Lysens R. Lumbosacral pain in an athlete. Clin Sports Med. 2002;21:93-103.

16. Duda M. Golfers use exercise to get back in the swing. Phys Sports Med.1989;17:109-13.

17. Micheli LJ, Wood R. Back pain in young athletes. Significant differences from adults in causes and patterns. Arch Pediatr Adolesc Med.1995;149(1):15-8.

18. Boden SD, Davis DO, Dina TS, Patronas NJ, Wiesel SW. Abnormal magnetic-resonance scans of the lumbar spine in asymptomatic subjects. A prospective investigation. J Bone Joint Surg Am. 1990;72(3):403-8.

19. Kirkaldy-Willis WH, Wedge JH, Yong-Hing K, Reilly J. Pathology and pathogenesis of lumbar spondylosis and stenosis. Spine (Phila Pa 1976). 1978;3(4):319-28.

20. Hutchinson MR. Low back pain in elite rhythmic gymnasts. Med Sci Sports Exerc. 1999;31(11):1686-8.

21. Morris FL, Smith RM, Payne WR, Galloway MA, Wark JD. Compres- sive and shear force generated in the lumbar spine of female rowers. Int J Sports Med. 2000;21(7):518-23.

22. Kibler WB, Chandler TJ. Range of motion in junior tennis players participating in an injury risk modification program. J Sci Med Sport. 2003;6(1):51-62.

23. Cosman ER, Nashold BS, Ovelman-Levitt J. Theoretical aspects of radiofrequency lesions in the dorsal root entry zone. Neurosurgery. 1984;15(6):945-50.

24. Trainor TJ, Trainor MA. Etiology of low back pain in athletes. Curr Sports Med Rep. 2004;3(1):41-6.

25. Cooke PM, Lutz GE. Internal disc disruption and axial back pain in the athlete. Phys Med Rehabil Clin N Am. 2000;11(4):837-65.

26. Rachbauer F, Sterzinger W, Eibl G. Radiographic abnormalities in the thoracolumbar spine of young elite skiers. Am J Sports Med. 2001;29(4):446-9.

27. Konttinen YT, Gronblad M, Antti-Poika I, Seitsalo S, Santavirta $S$, Hukkanen M, et al. Neuroimmunohistochemical analysis of peridiscal nociceptive neural elements. Spine (Phila Pa 1976). 1990;15(5):383-6.

28. Bogduk N, Tynan W, Wilson AS. The nerve supply to the human lumbar intervertebral discs. J Anat. 1981;132(Pt 1):39-56.

29. Sward L, Eriksson B, Peterson L. Anthropometric characteristics, passive hip flexion, and spinal mobility in relation to back pain in athletes. Spine (Phila Pa 1976). 1990;15(5):376-82.

30. Hosea TM, Gatt CJ, Carthy KE. Analytical computation of rapid dy namic loading of lumbar spine. Trans Orthop Res Soc. 1989;14:358.

31. Hosea TM, Hannafin JA. Rowing Injuries. Postgrad Adv Sport Med. 1989;111:1-17.

32. Gatt CJ, Hosea TM, Palumbo RC, Zawadsky JP. Impact loading of the lumbar spine during football blocking. Am J Sports Med. 1997;25(3):317-21.

33. Cholewicki J, McGill SM, Norman RW. Lumbar spine loads during the lifting of extremely heavy weights. Med Sci Sports Exerc. 1991;23(10):1179-86

34. Cappozzo A, Felici F, Figura F, Gazzani F. Lumbar spine loading during half-squat exercises. Med Sci Sports Exerc.1985;17(5):613-20.

35. Ong A, Anderson J, Roche J. A pilot study of the prevalence of lum bar disc degeneration in elite athletes with lower back pain at the Sydney 2000 Olympic Games. BrJ Sports Med. 2003;37(3):263-6.

36. Ogon M, Aleksiev AR, Spratt KF, Pope MH, Saltzman CL. Footwear affects the behavior of low back muscles when jogging. Int $J$ Sports Med. 2001;22(6):414-9.

37. Young JL, Press JM, Herring SA. The disc at risk in athletes: perspectives on operative and nonoperative care. Med Sci Sports Exerc. 1997;29(7 Suppl):S222-32.

38. Sward L, Hellstrom M, Jacobsson B, Peterson L. Back pain and radiologic changes in the thoraco-lumbar spine of athletes. Spine (Phila Pa 1976). 1990;15(2):124-9.

39. Green JP, Grenier SG, McGill SM. Low-back stiffness is altered with warm-up and bench rest: implications for athletes. Med Sci Sports Exerc. 2002;34(7):1076-81.

40. Nadler SF, Malanga GA, DePrince M, Stitik TP, Feinberg JH. The relationship between lower extremity injury, low back pain, and hip muscle strength in male and female collegiate athletes. Clin J Sport Med. 2000;10(2):89-97.

41. Kujala UM, Taimela S, Erkintalo M, Salminen JJ, Kaprio J. Low-back pain in adolescent athletes. Med Sci Sports Exerc. 1996;28(2):165-70.

42. Ogon M, Riedl-Huter C, Sterzinger W, Krismer M, Spratt KF, Wimmer C. Radiologic abnormalities and low back pain in elite skiers. Clin Orthop Relat Res. 2001;(390):151-62.

43. George SZ, Delitto A. Management of the athlete with low back pain. Clin Sports Med. 2002;21(1):105-20.

44. Bono CM. Low-back pain in athletes. JBone Joint Surg Am. 2004;86A(2):382-96.

45. Sairyo K, Sakai T, Yasui N. Conservative treatment of lumbar spondylolysis in childhood and adolescence: the radiological signs which predict healing.J Bone Joint Surg Br. 2009;91(2):206-9.

46. Petering RC, Webb C. Treatment options for low back pain in athletes. Sports Health. 2011;3(6):550-5.

47. Browning R, Jackson JL, O'Malley PG. Cyclobenzaprine and back pain: a meta-analysis. Arch Intern Med. 2001;161(13):1613-20.

48. Chou R, Huffman LH, American Pain S, American College of P. Medications for acute and chronic low back pain: a review 
of the evidence for an American Pain Society/American College of Physicians clinical practice guideline. Ann Intern Med. 2007;147(7):505-14.

49. Dagenais S, Gay RE, Tricco AC, Freeman MD, Mayer JM. NASS Contemporary Concepts in Spine Care: spinal manipulation therapy for acute low back pain. Spine J. 2010;10(10):918-40.

50. French SD, Cameron M, Walker BF, Reggars JW, Esterman AJ. A Cochrane review of superficial heat or cold for low back pain. Spine (Phila Pa 1976). 2006;31(9):998-1006.

51. Goldby LJ, Moore AP, Doust J, Trew ME. A randomized controlled trial investigating the efficiency of musculoskeletal physiotherapy on chronic low back disorder. Spine (Phila Pa 1976). 2006;31(10):1083-93.

52. Mayer JM, Ralph L, Look M, Erasala GN, Verna JL, Matheson LN, et al. Treating acute low back pain with continuous low-level heat wrap therapy and/or exercise: a randomized controlled trial. Spine J. 2005;5(4):395-403.

53. Ansari NN, Ebadi S, Talebian S, Naghdi S, Mazaheri H, Olyaei G et al. A randomized, single blind placebo controlled clinical trial on the effect of continuous ultrasound on low back pain. Electromyogr Clin Neurophysiol. 2006;46(6):329-36.

54. Nwuga VC. Ultrasound in treatment of back pain resulting from prolapsed intervertebral disc. Arch Phys Med Rehabil. 1983;64(2):88-9.

55. Roman MP. A clinical evaluation of ultrasound by use of a placebo technic. Phys Ther Rev.1960;40:649-52.

56. Yousefi-Nooraie R, Schonstein E, Heidari K, Rashidian A, Pennick $\mathrm{V}$, Akbari-Kamrani M, et al. Low level laser therapy for nonspecific low-back pain. Cochrane Database Syst Rev. 2008;(2):CD005107.

57. Roelofs PD, Deyo RA, Koes BW, Scholten RJ, van Tulder MW. Nonsteroidal anti-inflammatory drugs for low back pain: an updated Cochrane review. Spine (Phila Pa 1976). 2008;33(16):1766-74.

58. Urquhart DM, Hoving JL, Assendelft WW, Roland M, van Tulder MW. Antidepressants for non-specific low back pain. Cochrane Database Syst Rev. 2008;(1):CD0 01703.

59. Salerno SM, Browning R, Jackson JL. The effect of antidepressant treatment on chronic back pain: a meta-analysis. Arch Intern Med. 2002;162(1):19-24

60. Haimovic IC, Beresford HR. Dexamethasone is not superior to placebo for treating lumbosacral radicular pain. Neurology. 1986;36(12):1593-4.

61. Friedman BW, Holden L, Esses D, Bijur PE, Choi HK, Solorzano C, et al. Parenteral corticosteroids for Emergency Department patients with non-radicular low back pain. J Emerg Med. 2006;31(4):365-70.

62. Rubinstein SM, van Middelkoop M, Assendelft WJ, de Boer MR, van Tulder MW. Spinal manipulative therapy for chronic lowback pain: an update of a Cochrane review. Spine (Phila Pa 1976). 2011;36(13):E825-46.

63. Wegner I, Widyahening IS, van Tulder MW, Blomberg SE, de Vet HC, Bronfort G, et al. Traction for low-back pain with or without sciatica. Cochrane Database Syst Rev. 2013;8:CD003010.

64. Staal JB, de Bie R, de Vet HC, Hildebrandt J, Nelemans P. Injection therapy for subacute and chronic low-back pain. Cochrane Database Syst Rev. 2008;(3):CD001824.

65. Waseem Z, Boulias C, Gordon A, Ismail F, Sheean G, Furlan AD. Botulinum toxin injections for low-back pain and sciatica. $\mathrm{Co}$ chrane Database Syst Rev. 2011;(1):CD008257.

66. Furlan AD, van Tulder MW, Cherkin DC, Tsukayama H, Lao L, Koes BW, et al. Acupuncture and dry-needling for low back pain. Cochrane Database Syst Rev. 2005;(1):CD0 01351.

67. Furlan AD, Imamura M, Dryden T, Irvin E. Massage for low-back pain. Cochrane Database Syst Rev. 2008;(4):CD001929.

68. Heymans MW, van Tulder MW, Esmail R, Bombardier C, Koes BW. Back schools for non-specific low-back pain. Cochrane Database Syst Rev. 2004;(4):CD000261.

69. Assendelft WJ, Morton SC, Yu EI, Suttorp MJ, Shekelle PG. Spinal manipulative therapy for low back pain. Cochrane Database Syst Rev. 2004;(1):CD000447.

70. Hayden JA, van Tulder MW, Malmivaara A, Koes BW. Exercise therapy for treatment of non-specific low back pain. Cochrane Database Syst Rev. 2005;(3):CD000335.

71. Clarke JA, van Tulder MW, Blomberg SE, de Vet HC, van der Hei- jden GJ, Bronfort G, et al. Traction for low-back pain with or without sciatica. Cochrane Database Syst Rev. 2007;(2):CD0 03010

72. Standaert CJ, Herring SA, Halpern B, King O. Spondylolysis. Phys Med Rehabil Clin NAm. 2000;11(4):785-803.

73. Parker LM, Murrell SE, Boden SD, Horton WC. The outcome of posterolateral fusion in highly selected patients with discogenic low back pain. Spine (Phila Pa 1976). 1996;21(16):1909-16.

74. Johansen JG, McCarty DJ, Haughton VM. Retrosomatic clefts: computed tomographic appearance. Radiology.1983;148(2):447-8.

75. Rossi F, Dragoni S. Lumbar spondylolysis: occurrence in competitive athletes. Updated achievements in a series of 390 cases. $J$ Sports Med Phys Fitness. 1990;30(4):450-2.

76. Abraham T, Holder L, Silberstein C. The retroisthmic cleft. Scintigraphic appearance and clinical relevance in patients with low back pain. Clin Nucl Med.1997;22(3):161-5.

77. Kumar S, Sharma VP, Negi MP. Efficacy of dynamic muscular stabilization techniques (DMST) over conventional techniques in rehabilitation of chronic low back pain. J Strength Cond Res. 2009;23(9):2651-9.

78. Rackwitz B, de Bie R, Limm H, von Garnier K, Ewert T, Stucki G Segmental stabilizing exercises and low back pain. What is the evidence? A systematic review of randomized controlled trials. Clin Rehabil. 2006;20(7):553-67.

79. Fredrickson BE, Baker D, McHolick WJ, Yuan HA, Lubicky JP. The natural history of spondylolysis and spondylolisthesis. I Bone Joint Surg Am.1984;66(5):699-707.

80. Klein G, Mehlman CT, McCarty M. Nonoperative treatment of spondylolysis and grade I spondylolisthesis in children and young adults: a meta-analysis of observational studies. J Pediatr Orthop. 2009;29(2):146-56.

81. Sagi HC, Jarvis JG, Uhthoff HK. Histomorphic analysis of the development of the pars interarticularis and its association with isthmic spondylolysis. Spine (Phila Pa 1976). 1998;23(15):1635-9. discussion 1640.

82. Soler T, Calderon C. The prevalence of spondylolysis in the Spanish elite athlete. Am J Sports Med. 2000;28(1):57-62.

83. Jackson DW, Wiltse LL, Dingeman RD, Hayes M. Stress reactions involving the pars interarticularis in young athletes. Am J Sports Med.1981;9(5):304-12.

84. McTimoney CA, Micheli LJ. Current evaluation and management of spondylolysis and spondylolisthesis. Curr Sports Med Rep. 2003;2(1):41-6.

85. Brantigan JW, Steffee AD, Lewis ML, Quinn LM, Persenaire JM Lumbar interbody fusion using the Brantigan I/F cage for posterior lumbar interbody fusion and the variable pedicle screw placement system: two-year results from a Food and Drug Administration investigational device exemption clinical trial. Spine (Phila Pa 1976). 2000;25(11):1437-46.

86. Deshpande A, Furlan A, Mailis-Gagnon A, Atlas S, Turk D. Opioids for chronic low-back pain. Cochrane Database Syst Rev. 2007;(3):CD004959.

87. Khadilkar A, Odebiyi DO, Brosseau L, Wells GA. Transcutaneous electrical nerve stimulation (TENS) versus placebo for chronic low-back pain. Cochrane Database Syst Rev. 2008;(4):CD003008.

88. Kleeman TJ, Ahn UM, Talbot-Kleeman A. Laparoscopic anterior lumbar interbody fusion with rhBMP-2: a prospective study of clinical and radiographic outcomes. Spine (Phila Pa 1976). 2001;26(24):2751-6.

89. Kuslich SD, Ulstrom CL, Griffith SL, Ahern JW, Dowdle JD. The Bagby and Kuslich method of lumbar interbody fusion. History, techniques, and 2-year follow-up results of a United States prospective, multicenter trial. Spine (Phila Pa 1976). 1998;23(11):1267-78.

90. Sys J, Michielsen J, Bracke P, Martens M, Verstreken J. Nonoperative treatment of active spondylolysis in elite athletes with normal X-ray findings: literature review and results of conservative treatment. Eur Spine J. 2001;10(6):498-504.

91. d'Hemecourt PA, Gerbino P2, Micheli LJ. Back injuries in the young athlete. Clin Sports Med. 2000;19(4):663-79.

92. Iwamoto J, Takeda T, Wakano K. Returning athletes with severe low back pain and spondylolysis to original sporting activities with conservative treatment. Scand J Med Sci Sports. 2004;14(6):346-51. 
93. Graw BP, Wiesel SW. Low back pain in the aging athlete. Sports Med Arthrosc. 2008;16(1):39-46.

94. Keene JS, Drummond DS. Mechanical back pain in the athlete. ComprTher.1985;11(1):7-14.

95. Eck JC, Riley L3. Return to play after lumbar spine conditions and surgeries. Clin Sports Med. 2004;23(3):367-79.

96. Iwamoto J, Sato Y, Takeda T, Matsumoto H. The return to sports activity after conservative or surgical treatment in athletes with lumbar disc herniation. Am J Phys Med Rehabil. 2010;89(12):1030-5.

97. Fehlandt AJ, Micheli LJ. Lumbar facet stress fracture in a ballet dancer. Spine (Phila Pa 1976). 1993;18(16):2537-9.

98. Amato M, Totty WG, Gilula LA. Spondylolysis of the lumbar spine: demonstration of defects and laminal fragmentation. Radiology. 1984;153(3):627-9.

99. Roche MB, Rowe GG. The incidence of separate neural arch and coincident bone variations; a survey of 4,200 skeletons. Anat Rec. 1951;109(2):233-52.

100. Collier BD, Johnson RP, Carrera GF, Meyer GA, Schwab JP, Flatley TJ, et al. Painful spondylolysis or spondylolisthesis studied by radiography and single-photon emission computed tomography. Radiology. 1985;154(1):207-11.

101. Blanda J, Bethem D, Moats W, Lew M. Defects of pars interarticularis in athletes: a protocol for nonoperative treatment. J Spinal Disord. 1993;6(5):406-11. 